\title{
Prognostic Significance of Standardized Uptake Value of PET Scan in Non-Small Cell Lung Cancer
}

\author{
A. Alshuhayeb*, S. Gilbert, A. J. E. Seely, F. M. Shamji, S. Sundaresan, P. J. Villeneuve, \\ D. E. Maziak \\ Division of Thoracic Surgery, University of Ottawa, The Ottawa Hospital, General Campus, Ottawa, Canada \\ Email: *aalshuhayeb@gmail.com
}

Received 30 January 2016; accepted 15 March 2016; published 18 March 2016

Copyright (C) 2016 by authors and Scientific Research Publishing Inc.

This work is licensed under the Creative Commons Attribution International License (CC BY). http://creativecommons.org/licenses/by/4.0/

(c) (i) Open Access

\section{Abstract}

Background: To determine if the maximum standardized uptake value (SUVmax) of the primary tumor as determined by preoperative (18)F-fluoro-2-deoxyglucose ((18)F-FDG) positron emission tomography (PET) is an independent predictor of overall survival, mediastinal lymph node metastasis, and stage in patients with non-small cell lung cancer (NSCLC). Methods: A retrospective review of 1033 patients with stage I-IV histologically proven NSCLC who had an (18)F-FDG PET done between 2005 and 2011 for staging before receiving therapy was performed. SUVmax of primary NSCLC was measured and correlated with tumor characteristics, lymph node involvement, cancer stage and overall survival. The patients were divided into three groups according to their SUVmax value: group I SUVmax < 5; group II SUVmax 5 - 10; and group III SUVmax > 10. The primary outcome was survival and recurrence rate, compared using Log Rank Test. Results: The median duration of follow up was 675 days (22.5 months). The overall survival at two years for group I was $88 \%$, group II $60 \%$ and group III $53 \%$, significantly different among the three groups (p-value < 0.0001). Earlier stage lung cancer was found in patients with lower SUVmax values: in group I, 73\% of patients had stage I cancer and only $4 \%$ had stage IV. The rate of ipsilateral mediastinal lymph node involvement (N2) in group I was $12.9 \%$ compared to $44.4 \%$ in group III (p-value $<0.0001$ ). The overall survival was significantly different between group I and group II (Hazard Ratio (HR) 3.6; 95\% C.I $2.2-5.7$ and a p-value $<0.0001$ ) and between group II and group III (HR 1, 4; 1.1 - 1.8 and a p-value $=0.013$ ). Conclusion: There was a statistically significant difference in the overall survival, mediastinal lymph node metastases, and higher cancer stage with greater values of SUVmax on PET scan in patients with NSCLC.

\footnotetext{
"Corresponding author.
} 


\section{Keywords}

\section{Non Small Cell Lung Cancer, SUV, PET, Prognosis}

\section{Introduction}

Lung cancer is the most common cause of cancer death in the world and the second most common cancer in both men and women [1]. Non small-cell lung cancer (NSCLC) comprises 80\% to 85\% of all lung cancer cases. Accurate staging of NSCLC plays an important role in stratifying patients for optimal treatment regimens and improving prognosis.

(18)F-fluoro-2-deoxyglucose ((18)F-FDG) (18F-FDG) positron emission tomography (PET) is a non-invasive imaging technique for the evaluation of unidentified pulmonary nodules, the diagnosis of lung cancer, the staging of mediastinal lymph nodes, the evaluation of distant metastases and response to therapy [2] [3]. Integrated PET-CT scan combines the functional characteristic of the PET scan with the anatomic features of the CT scan which improved the diagnoses and staging accuracy [4]. PET-CT scan alters the stage designation and management in as many as $20 \%$ to $40 \%$ of patients [5]. It is based on the observation that metabolically active cells selectively take up and trap fluoridated glucose, which then undergoes nuclear decay that can be detected, localized, and quantified [6].

To better understand the potential contribution of SUV to determine prognosis, we reviewed the records of patients with NSCLC after PET-CT imaging. Data were analyzed to determine whether SUV predicted the overall survival, recurrence rate, the likelihood of lymph node involvement and if so, whether SUV was an independent prognostic factor for survival from components of pathologic tumor node-metastasis system staging.

\section{Patients and Methods}

\subsection{Patient Characteristics}

All patients with non-small cell lung cancer diagnosis were reviewed between January 2005 and December 2011. We identified 1523 patients and their charts were reviewed. All stages of NSCLC were included in our review provided that a PET-CT scan was performed as part of the staging investigation (Figure 1). There were 449 patients excluded from the study due to diagnosis of other malignancy in the last 5 years or the PET-CT scan was

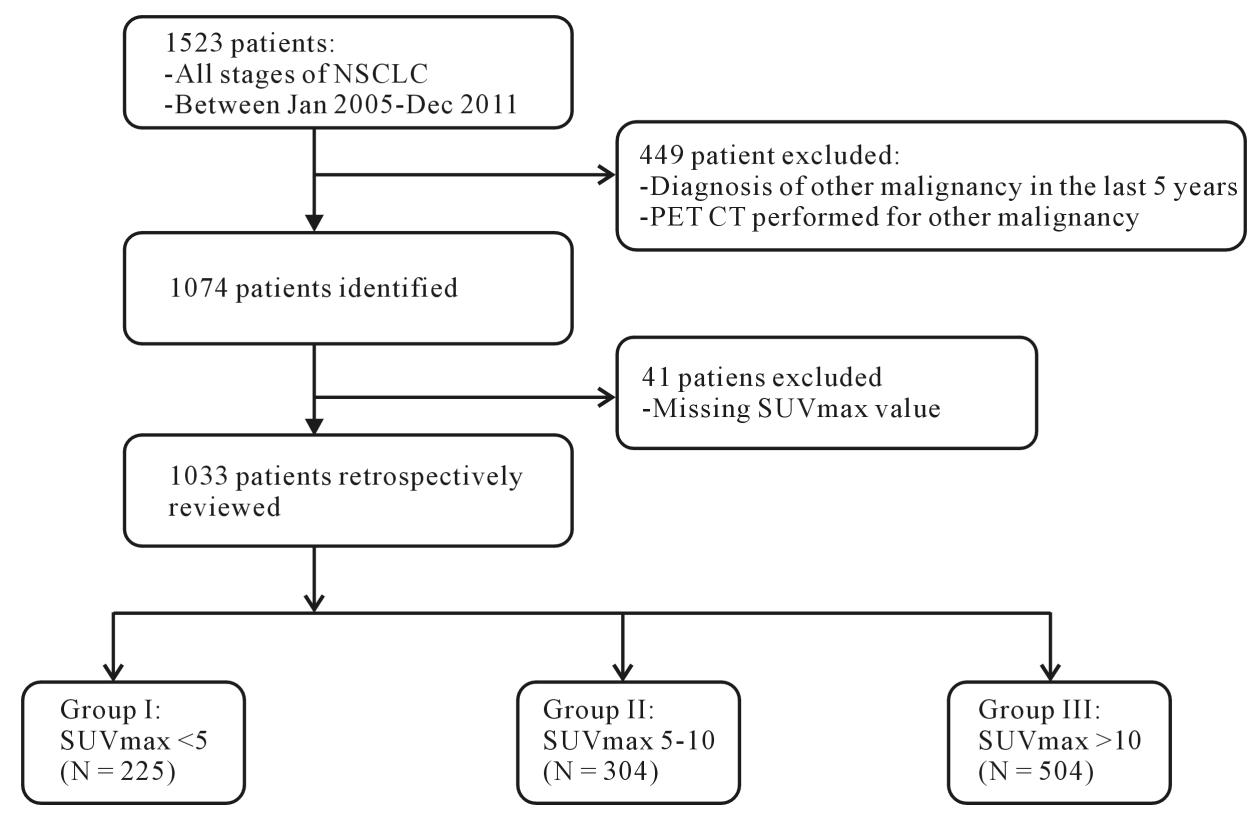

Figure 1. Flow chart showing all patients reviewed during study period and those excluded. 
performed for diagnosis or staging another malignancy. A retrospective review of 1074 patients with a diagnosis of NSCLC (stage I-IV) was performed. A total of 1033 patients were included in the final analysis after excluding 41 patients due to missing data. If the PET-CT scan was performed as part of the work up for a recurrent NSCLC but not performed during the staging of the initial disease the patients were excluded. We did not include any patient who received any form of chemotherapy or radiation therapy during a period of 5 years prior to the diagnoses of NSCLC.

The patients were divided into 3 groups according to their SUVmax value in the primary lung tumor: group I with SUVmax < 5; group II with SUVmax between 5 - 10; and group III with SUVmax > 10. These ranges were selected based on convenience, and to assure reasonable numbers in all groups (>20\% per group).

All patients had an integrated PET-CT scan performed at the same PET center with the same scanner to complete the disease work up and staging. Patients clinical characteristics, demographic data, tumor features, radiological and pathological findings were analyzed retrospectively through the review of patients charts, pathological and radiological reports. The SUVmax were measured prospectively in all patients. The study was approved by the institutional review board.

\subsection{PET-CT Imaging}

The PET-CT scan was performed using integrated PET-CT scanner (Philips Gemini Dual Exp PET-CT scanner). Patients were fasting at least for 4 hours prior to the procedure and the image were obtained 1 hour after intravenous injection of 18-FDG. Patients remained resting for an uptake period of 1 hour. Images were obtained from the base of the skull to the mid-thigh level. Then, the PET data was acquired in 3-dimensional mode followed by data sets reconstruction into coronal, sagittal and axial views. Attenuation corrected images were obtained and interpreted by an experienced nuclear medicine physician.

The primary lesions were considered positive if a definite localized area of high 18-FDG uptake more than the surrounding normal tissue exists (not including the physiological uptake). The same principle was applied for the nodal uptake with the SUVmax measurement. The SUVmax of the primary tumor was measured with a region of interest technique and calculated by the software according to standard formulas.

\subsection{Data Collection}

The primary tumor and the mediastinal lymph node SUVmax was obtained from the initial PET reports. An exclusion of 41 patient occurred due to missing information on the SUVmax on the radiology report. The biopsy results of the primary tumor, mediastinal staging procedure and the results of the final resection specimen were obtained from the pathology report without adjudication. Baseline demographic, clinical, and tumor characteristics, treatment, follow-up, and survival data were obtained from the electronic medical record system of the hospital.

\subsection{Statistical Methods}

The Kaplan-Meier Curve was plotted to show the overall survival in the cohort. The Kaplan-Meier Curves and the Log Rank Test was calculated to compare the overall survival between the 3 groups. Log Rank Test was performed to find statistical differences.

Cox Regression analysis was used to estimate the crude hazard ratio for levels of SUV.

Multivariable Cox modeling was used to adjust for effect of final stage. Hazard ratios and 95\% confidence intervals were calculated. A p value $<0.05$ was considered statistically significant.

\section{Results}

There were a total of 1033 patients included and their characteristics are shown in Table 1 . The median follow up was 22.5 months (inter-quartile range 12.1 - 34.4). The lowest number of patients was in group I-SUVmax $<5$ with 225 patients (21.7\%) followed by group II-SUVmax 5 - 10 with 304 patients (29.4\%) and then group III-SUVmax > 10 with 504 patients (48.7\%). The mean age for all groups was between 70.7 - 71.9 years, and there was no statistically significant difference between the groups. There was a slight female predominance in group I (59\%) compared to group II (56\%) and group III (47\%). Mean SUVmax (Figure 2) in group I was 3.2, in group II was 7.7 and 16 in group III. The most common tumor location was the right upper lobe in all the 3 
Table 1. Patient characteristics.

\begin{tabular}{lcccc}
\hline & $\begin{array}{c}\text { SUV }<5 \\
(\mathrm{n}=225)\end{array}$ & $\begin{array}{c}5 \leq \mathrm{SUV} \leq 10 \\
(\mathrm{n}=304)\end{array}$ & $\begin{array}{c}\text { SUV }>10 \\
(\mathrm{n}=504)\end{array}$ & p-value \\
\hline Age & & & \\
Mean (Std) & $70.9(9.96)$ & $71.7(9.6)$ & $71.4(9.6)$ & 0.666 \\
Female & $133(59)$ & $169(56)$ & $236(47)$ & 0.0031 \\
$\quad$ N (\%) & & & \\
Size of tumor & $21.9(11.5)$ & $32.3(18.2)$ & $46.3(22.6)$ & $<0.0001$ \\
Mean (Std) & & & & \\
Location & $35(16)$ & $37(12)$ & $46(9)$ & \\
LLL & $51(23)$ & $101(33)$ & $173(34)$ & \\
LUL & $52(23)$ & $49(16)$ & $82(16)$ & \\
RLL & $5(2)$ & $11(4)$ & $28(6)$ & \\
RML & $81(36)$ & $106(35)$ & $173(34)$ & \\
RUL & &
\end{tabular}

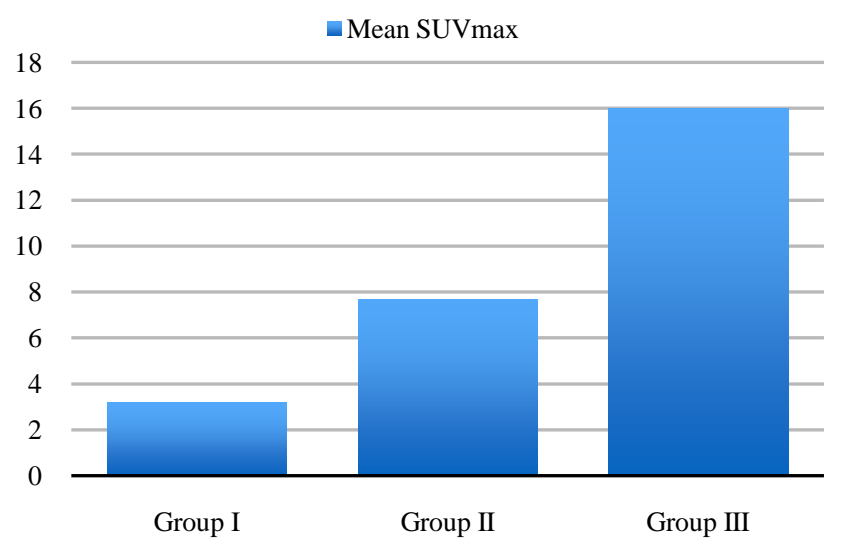

Figure 2. Mean SUVmax in different groups.

groups (34\% - 36\%) followed by the left upper lobe (23\% - 34\%). The least common tumor location among all the groups was the right middle lobe (2\% - 6\%). Upon examination of the primary tumour, the mean SUVmax in group I was 2.2; group II was 6.8; and group III was 15.9. There was a significant difference in the mean tumor size of the primary lung lesion among all the groups, were the mean tumor size (Figure 3) of group I was 21.9 mm compared to group II $32.3 \mathrm{~mm}$ and group III $46.3 \mathrm{~mm}$ (p-value < 0.0001).

There was a significant difference in tumor stage distribution among all the 3 groups (Table 2). In group I 73\% of patients were stage I compared to $12 \%$ with stage III and $4 \%$ with stage IV. In group II the difference was also noticed as $50 \%$ of patients in this group were stage I compared to $16 \%$ with stage IV. In group III $19 \%$ were stage I, 39\% were stage II and 20\% were stage III. A total of 412 patients in all the cohort had a stage I tumor among which 73\% in group I had a SUVmax < 5 compared to $19 \%$ in group III where the SUVmax $>10$ (p-value < 0.0001). Stage IV patients (160 patients) were found more in Group III (20\%) compared to group I (4\%) with a p-value of $<0.0001$. Metastasis to mediastinal lymph nodes (N2) were found in $12.9 \%$ of group I, $29.3 \%$ of group II and $44.4 \%$ in group III (p-value $<0.0001$ ). Contralateral mediastinal lymph node metastasis (N3) were found in $4.9 \%$ of group I, $7.7 \%$ of group II and $12.5 \%$ of group III. A significant difference was observed on the rate of distant metastasis among the three groups with 3.1\% of group I, 13.2\% of group II and $19.4 \%$ of group III (p-value < 0.0001). 


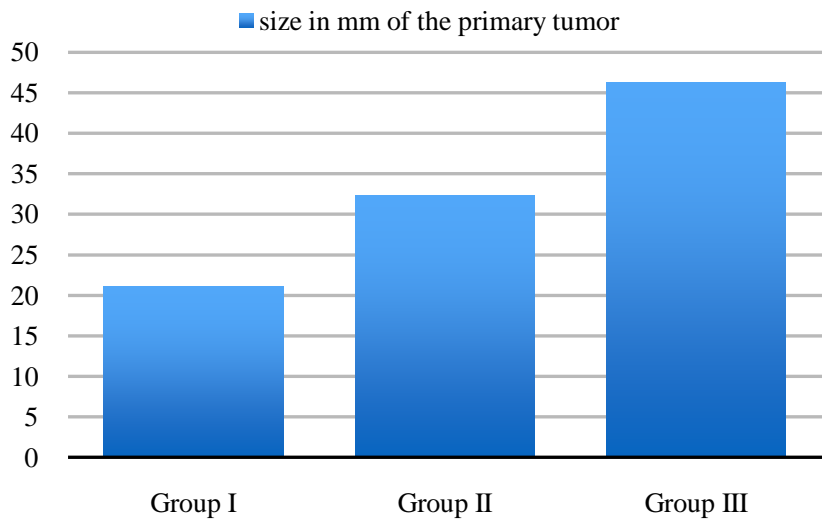

Figure 3. Mean size of the primary tumor in different groups.

Table 2. Tumor stage and mediastinal lymph node involvement.

\begin{tabular}{|c|c|c|c|c|c|}
\hline & & $\begin{array}{l}\text { Group I } \\
\text { SUV }<5 \\
(n=225)\end{array}$ & $\begin{array}{c}\text { Group II } \\
5 \leq \text { SUV } \leq 10 \\
(n=304)\end{array}$ & $\begin{array}{l}\text { Group III } \\
\text { SUV }>10 \\
(n=504)\end{array}$ & p-value \\
\hline \multicolumn{6}{|c|}{ PET CT Stage: } \\
\hline I & & 164 (73\%) & $151(50 \%)$ & 97 (19\%) & \multirow{4}{*}{$<0.0001$} \\
\hline II & & $23(10 \%)$ & $36(12 \%)$ & 109 (22\%) & \\
\hline III & & $28(12 \%)$ & $68(22 \%)$ & 197 (39\%) & \\
\hline IV & & $10(4 \%)$ & 49 (16\%) & $101(20 \%)$ & \\
\hline \multicolumn{6}{|c|}{ Mediastinal LN: } \\
\hline $\mathrm{N} 1$ & N (\%) & $34(15.1 \%)$ & 80 (26.3\%) & 217 (43.1\%) & $<0.0001$ \\
\hline N2 & N (\%) & 29 (12.9\%) & 89 (29.3\%) & 224 (44.4\%) & $<0.0001$ \\
\hline N3 & N (\%) & $11(4.9 \%)$ & $23(7.7 \%)$ & 63 (12.5\%) & 0.0024 \\
\hline \multicolumn{6}{|c|}{ Metastasis: } \\
\hline $\mathrm{M}(\mathrm{c}$ & & 7 (3.1\%) & 40 (13.2\%) & 98 (19.4\%) & $<0.0001$ \\
\hline
\end{tabular}

The median follow-up was 22.5 months (Inter-quartile Range, 12.1 - 34.4). The overall survival was $82 \%$ and $63 \%$ at 1 and 2 years from the time of diagnosis. The median survival for all patients was equal 2.99 years (95\% confidence interval: 2.7, 3.5). The overall survival for group I at one and two years was $95 \%$ and $88 \%$. The overall survival for group II at one and two years was $81 \%$ and $60 \%$. The overall survival for group III at one and two years was $76 \%$ and 53\%. Kaplan Meyer curves (Figure 4) show that patients in group I has a better survival compare to the two other groups. The Log Rank Test showed that the overall survival was significantly different among patients in the three groups at $\alpha=0.05$ (P-value $<0.0001$ ). The hazard ratio for group II (3.05) and group III (3.63) compared to group I was significantly higher. The hazard ratio for group II was not significantly higher than the hazard ratio for group III (1.19) (Table 3). The survival benefit of lower SUVmax value was clearly demonstrated in stage IA and IB as shown (Figure 5, Figure 6) by Kaplan Meyer curves (p-value of 0.0011 and 0.0066 respectively). In more advanced stages of lung cancer the survival benefit of lower SUVmax value was not demonstrated (Figure 7, Figure 8). Recurrence free survival of group I at one and two years was $91 \%$ and $85 \%$ respectively. In group II the recurrence free survival at one and two years was $83 \%$ and $67 \%$ respectively and in group III, $79 \%$ and $56 \%$.

We studied the relationship between the SUVmax value results of the ipsilateral (N2) and contralateral lymph nodes (N3) compared to the final pathology results (obtained from cervical mediastinoscopy, endobronchial ultrasound biopsy and the final pathology results in resected specimens) in predicting mediastinal lymph node metastasis (Table 4). A total of 537 patients in whom the final pathology results were collected. The specificity 
Table 3. Hazard ratio in univariable analysis for survival.

\begin{tabular}{lcccc}
\hline \multicolumn{1}{c}{ Effect } & $\begin{array}{c}\text { Crude Hazard } \\
\text { Ratio }\end{array}$ & $\begin{array}{c}\text { 95\% C.I. } \\
\text { Lower }\end{array}$ & $\begin{array}{c}\text { 95\% C.I. } \\
\text { Upper }\end{array}$ & p-value \\
\hline SUV & 3.05 & 2.18 & 4.25 & $<0.0001$ \\
Group I vs group II & 3.63 & 2.65 & 4.97 & $<0.0001$ \\
Group I vs group III & 1.19 & 0.98 & 1.45 & 0.084 \\
Group II vs group III & & & & \\
\hline
\end{tabular}

Table 4. SUVmax value of the mediastinal lymph nodes (N2, N3) vs final pathology specimen, cervical mediastiniscopy and EBUS.

\begin{tabular}{ccccc}
\hline & Sensitivity & Specificity & $\begin{array}{c}\text { Positive predictive } \\
\text { value }\end{array}$ & $\begin{array}{c}\text { Negative predictive } \\
\text { value }\end{array}$ \\
\hline N2 & $62 \%$ & $82 \%$ & $50 \%$ & $88 \%$ \\
N3 & $58 \%$ & $73 \%$ & $63 \%$ & $98 \%$ \\
\hline
\end{tabular}

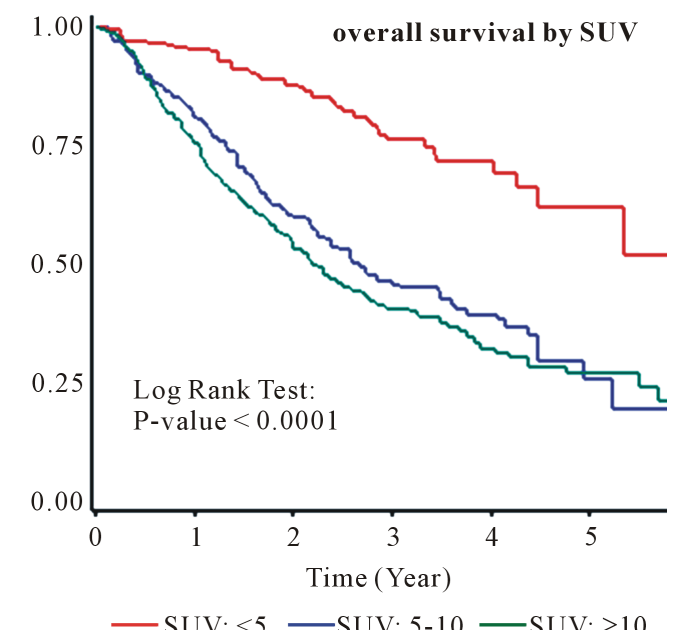

Figure 4. The overall survival by SUVmax.

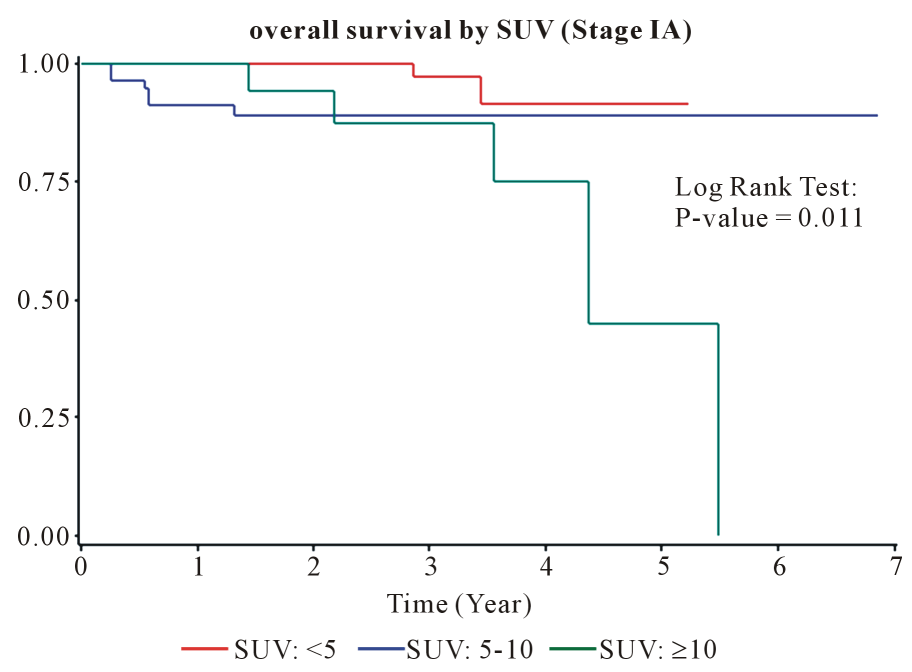

Figure 5. The overall survival for stage IA. 


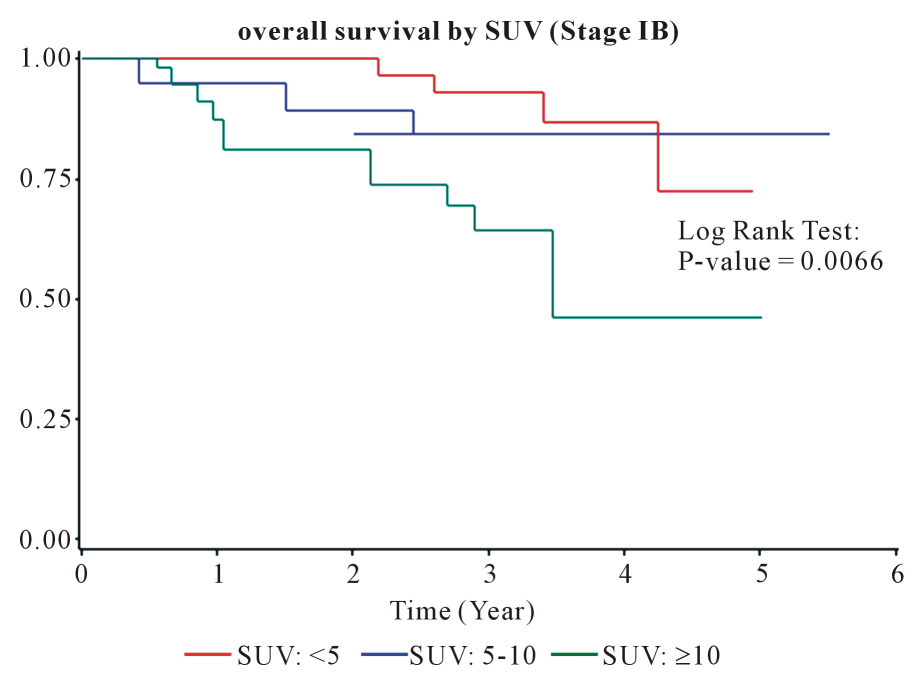

Figure 6. The overall survival for stage IB.

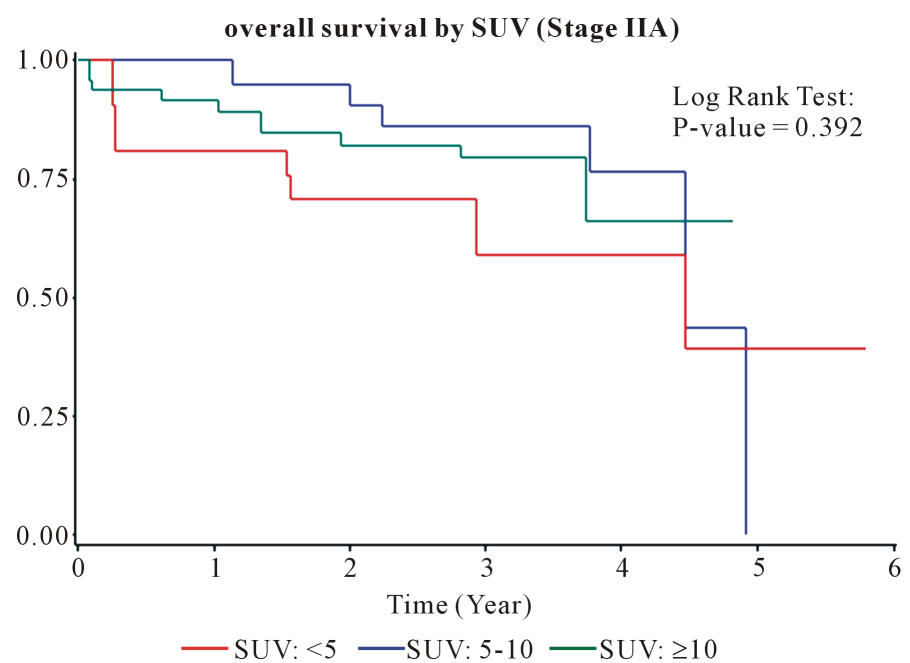

Figure 7. The overall survival for stage IIA.

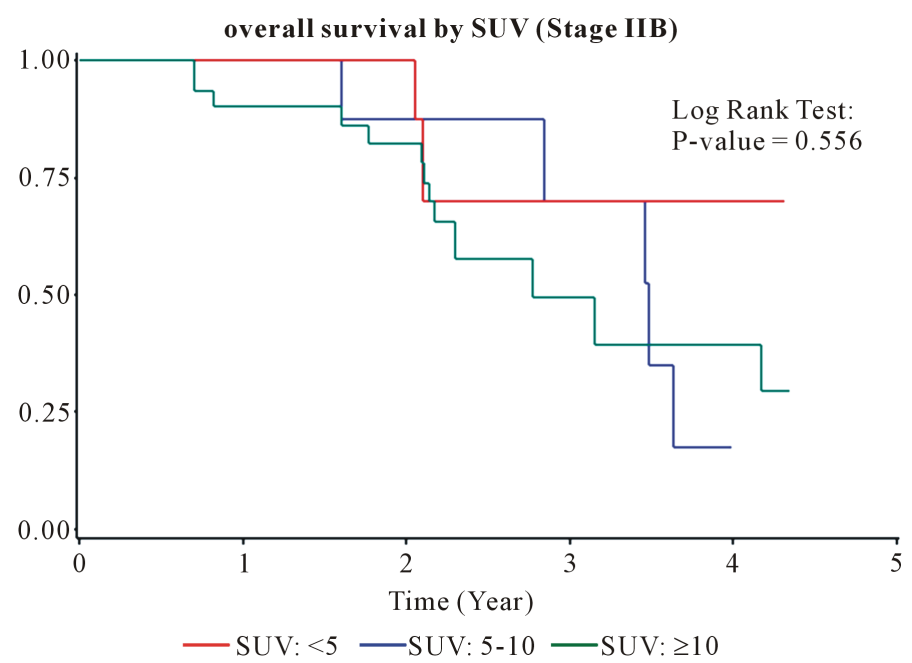

Figure 8. The overall survival for stage IIB. 
was high at $82 \%$ for N2 disease based on SUVmax values compared to the final pathology. A high negative predictive value at $88 \%$ for $\mathrm{N} 2$ disease was noticed but the sensitivity was $62 \%$ and the positive predictive value was $50 \%$. For N3 disease a high negative predictive value was clearly demonstrated at $98 \%$. The sensitivity, specificity and positive predictive value were $58 \%, 73 \%$ and $63 \%$ respectively.

A survival analysis was performed on a group of patients for whom bronchoscopy was done as part of evaluation of their lung cancer and whether the presence of endobronchial lesion was a poor prognostic factor. A total of 662 patients were included in this analysis. The log Rank Test showed that patients with visible endobronchial lesion had a lower survival compare to patients without endobronchial lesion (p-value $<0.0001$ ). The hazard function for visible endobronchial lesion was significantly higher than the hazard function for patients with no endobronchial lesions, Hazard ratio 2.46 (95\% CI 1.91 - 3.18).

\section{Discussion}

The TNM staging system for NSCLC is an important tool used by clinicians to estimate lung cancer prognosis and ensure stage appropriate treatment. The TNM staging system does not consistently give a satisfactory explanation for differences in survival, hence it is important to identify other prognostic factors. Integrated PET-CT has become the standard imaging modality in the staging of NSCLC patients. The main applications of PET-CT are: First, it is used in screening for regional and distant metastasis as part of staging. [7]. Second, it is useful in monitoring response to treatment for patients having chemotherapy and/or radiation therapy [8]. [18F]FDG-PET imaging is based on the rate of glucose metabolism; with data suggesting that the rate of tumor metabolic activity may correlate with tumor aggressiveness, PET is the modality of choice to complement the prognostic information provided by the CT [9].

SUV is a semi-quantitative parameter that is calculated from the concentration of radioactivity adjusted by body weight and dose of injected [18F]FDG. SUVmax is the preferred indicator in the evaluation of PET-CT images. A recent study has shown that SUVmax is a more accurate and reliable value than the mean SUV and the tumor volume-correlated SUV in the interpretation of PET images [10]. In a study done by Iskender et al. and published in 2011 it showed that SUVmax is relatively consistent from one PET center to another even using different scanners; thus, SUV max is a valuable measure for comparison among all centers [11]. However, other studies reported SUVmax variability between centers due to lack of standardisation in acquisition and processing protocols [12] [13]. Other technical variations between PET centers are related to image reconstruction, analysis, and attenuation correction. Also, physiologic factors can affect SUVmax value and cause variation between scanners like blood glucose level, patient respiratory movement during image acquisition, duration between administration of FDG and image acquisition, inflammation around tumor, serum level of insulin and renal clearance of FDG [14] [15].

Improved survival in NSCLC patients treated with neoadjuvant chemotherapy has been shown in recently published data [16]. This might replace the way of conventional practice of adjuvant chemotherapy following resection. Still the data available is limited on preoperative prognostic indicator that might change the decision on when patients should receive adjuvant or neoadjuvant chemotherapy. A question on who should receive adjuvant therapy after resection remains unanswered in the treatment of NSCLC. Patients with poor prognostic indicators could be treated more aggressively with neoadjuvant chemotherapy while those with favourable prognostic indicators could be treated postoperatively with adjuvant type chemotherapy based on their surgical pathological stage.

Our results show that there is a significant correlation between the tumor size and the SUVmax value. Lower levels of SUVmax are associated with smaller primary lung tumors. It was also shown that the minority of patients with lower levels of SUVmax (group I) have advanced stage IV lung cancer (only 4\%) compared to the majority of early stage I lung cancer (73\%). The rate of ipsilateral and contralateral mediastinal lymph nodes metastasis (N2, N3) was significantly higher in patients with higher levels of SUVmax. Cerfolio et al. have shown in there study that the SUVmax of NSCLC is positively correlated to the T status, N status, and M status and is an independent predictor of stage. They stated that SUVmax might even be a better guide than the clinical stage [17].

This study has shown that survival decreases as the SUVmax of the primary tumour increases. We thought that it was important to analyze the correlation of SUVmax with survival within each clinical stage. The survival benefit of lower SUVmax was most pronounced in stage IA and IB, but it was not demonstrated in the other 
lung cancer stages. Okereke et al. reported the same results in 2009. He found that the group of patients with no clinical evidence of disease in the mediastinum had a better prognosis [18]. These findings are important in that they can perhaps guide treatment plan based on these values, as the SUVmax levels are known preoperatively. Some centres now use SUVmax mainly as an "all or none” value, with values above 2.5 considered positive. The results of this study argue that the SUVmax should instead be used as a gradient, and higher values could potentially alter overall treatment plan. Decisions about whether to perform mediastinoscopy before resection, the need for adjuvant therapy, and the frequency of postoperative surveillance all may be affected by preoperative SUVmax levels.

Previous studies have correlated FDG uptake in primary tumor correlates with poor survival. Most of these studies were based on comparisons of survival between groups of patients with high and low SUV values, defined by applying cut-offs for SUV ranging from 5 to 20 [9] [17] [19]-[30]. There is apparently no true cut-offs point for SUV, but rather a transition zone in which the prognosis gradually worsens. A systematic review done by Nair et al. concluded that increasing tumor FDG uptake is associated with worse survival in patients with stage I NSCLC [31].

Limitations of the study include the retrospective nature of the data, but it is the largest published series on this topic. Another limitation is that adjudication was not performed for the reports of PET, SUVmax and pathology. Also, there is a selection bias as we excluded patients who had received neoadjuvant treatment. The results of this study might not be applied for patients with greatly metastatic NSCLC. Lastly, the cutoffs for the SUV values in the 3 groups were somewhat arbitrary.

\section{Conclusion}

There was a statistically significant difference in the overall survival and a higher cancer stage with higher values of SUVmax on PET scan in patients with NSCLC. The results were more pronounced in stage I tumors. Using different zones of SUVmax value might be more reliable prognostic factor than using SUVmax cut-off points. Such information may help in selecting patients preoperatively into receiving neoadjuvant chemotherapy.

\section{References}

[1] Parkin D.M., Bray, F.I. and Devesa, S.S. (2001) Cancer Burden in the Year 2000: the Global Picture. European Journal of Cancer, 37, S4e66. http://dx.doi.org/10.1016/s0959-8049(01)00267-2

[2] Bunyaviroch, T. and Coleman, R.E. (2006) PET Evaluation of Lung Cancer. Journal of Nuclear Medicine, 47, 451469.

[3] Bruzzi, J.F. and Munden, R.F. (2006) PET/CT Imaging of Lung Cancer. Journal of Thoracic Imaging, 21, $123-136$. http://dx.doi.org/10.1097/00005382-200605000-00004

[4] Steinert, H.C. (2010) PET and PET-CT of Lung Cancer. Methods in Molecular Biology, 727, 33-51. http://dx.doi.org/10.1007/978-1-61779-062-1_3

[5] Reed, C.E., Harpole, D.H., Posther, K.E., et al. (2003) American College of Surgeons Oncology Group Z0050 Trial. Results of the American College of Surgeons Oncology Group Z0050 Trial: The Utility of Positron Emission Tomography in Staging Potentially Operable Non-Small Cell Lung Cancer. The Journal of Thoracic and Cardiovascular Surgery, 126, 1943-1951. http://dx.doi.org/10.1016/j.jtcvs.2003.07.030

[6] Stroobants, S.G., D’Hoore, I., Dooms, C., et al. (2003) Additional Value of Wholebody Fluorodeoxyglucose Positron Emission Tomography in the Detection of Distant Metastases of Non-Small-Cell Lung Cancer. Clinical Lung Cancer, 4, 242-247. http://dx.doi.org/10.3816/CLC.2003.n.005

[7] Maziak, D.E., Darling, G.E., Inculet, R.I., Gulenchyn, K.Y., et al. (2009) The Impact of Positron Emission Tomography (PET) Imaging in Staging Potentially Surgically Resectable Non-Small Cell Lung Cancers: A Prospective, Multicenter Randomized Clinical Trial ELPET. Annals of Internal Medicine, 151, 221-228. http://dx.doi.org/10.7326/0003-4819-151-4-200908180-00132

[8] Skoura, E., Datseris, I.E., Platis, I., et al. (2012) Role of Positron Emission Tomography in the Early Prediction of Response to Chemotherapy in Patients with Non-Small-Cell Lung Cancer. Clinical Lung Cancer, 13, 181-187. http://dx.doi.org/10.1016/j.cllc.2011.05.004

[9] Downey, R.J., Akhurst, T., Gonen, M., et al. (2004) Pre-Operative F-18 Fluorodeoxyglucose-Positron Emission Tomography Maximal Standardized Uptake Value Predicts Survival after Lung Cancer Resection. Journal of Clinical Oncology, 22, 3255-3260. http://dx.doi.org/10.1200/JCO.2004.11.109

[10] Degirmenci, B., Wilson, D., Laymon, C.M., Becker, C., Mason, N.S., Bencherif, B., Agarwal, A., Luketich, J., Lan- 
dreneau, R. and Avril, N. (2008) SUV-Based Evaluations of Solitary Pulmonary Nodules Using FDG-PET/CT. Nuclear Medicine Communications, 29, 614-622. http://dx.doi.org/10.1097/MNM.0b013e3282f9b5a0

[11] Iskender, I., kadioglu, S., Kosar, A., Atasalihi, A. and Kir, A. (2011) Is There Any Maximum Standardized Uptake Value Variation among Positron Emission Tomography Scanners for Mediastinal Staging in Non-Small Cell Lung Cancer? Interactive Cardiovascular and Thoracic Surgery, 12, 965-969. http://dx.doi.org/10.1510/icvts.2010.258103

[12] Paesmans, M., Berghmans, T., Dusart, M., et al. (2010) Primary Tumor Standardized Uptake Value Measured on Fluorodeoxyglucose Positron Emission Tomography Is of Prognostic Value for Survival in Non-Small Cell Lung Cancer: Update of a Systematic Review and Meta-Analysis by the European Lung Cancer. Working Party for the International Association for the Study of Lung Cancer Staging Project. Journal of Thoracic Oncology, 5, 612-619. http://dx.doi.org/10.1097/JTO.0b013e3181d0a4f5

[13] Kanstrup, I.L., Klausen, T.L., Bojsen-Møller, J., et al. (2009) Variability and Reproducibility of Hepatic FDG Uptake Measured as SUV as well as Tissue-To-Blood Background Ratio Using Positron Emission Tomography in Healthy Humans. Clinical Physiology and Functional Imaging, 29, 108-113. http://dx.doi.org/10.1111/j.1475-097X.2008.00846.x

[14] Kubota, K., Watanabe, H., Murata, Y., et al. (2011) Effects of Blood Glucose Level on FDG Uptake by Liver: A FDGPET/CT Study. Nuclear Medicine and Biology, 38, 347-351. http://dx.doi.org/10.1016/j.nucmedbio.2010.09.004

[15] Boellaard, R., Oyen, W.J., Hoekstra, C.J., et al. (2008) The Netherlands Protocol for Standardisation and Quantification of FDG Whole Body PET Studies in Multi-Centre Trials. European Journal of Nuclear Medicine and Molecular Imaging, 35, 2320-2333. http://dx.doi.org/10.1007/s00259-008-0874-2

[16] Depierre, A., Milleron, B., Moro-Sibilot, D., Chevret, S., Quoix, E., Lebeau, B., Braun, D., Breton, J.L., Lemarie, E., Gouva, S., Paillot, N., Brechot, J.M., Janicot, H., Lebas, F.X., Terrioux, P., Clavier, J., Foucher, P., Monchatre, M., Coetmeur, D., Level, M.C., Leclerc, P., Blanchon, F., Rodier, J.M., Thiberville, L., Villeneuve, A., Westeel, V., Chastang, C. and French Thoracic Cooperative Group (2002) Preoperative Chemotherapy Followed by Surgery Compared with Primary Surgery in Resectable Stage I (Except T1N0), II, and IIIa Non-Small-Cell Lung Cancer. Journal of Clinical Oncology, 20, 247-253. http://dx.doi.org/10.1200/JCO.20.1.247

[17] Cerfolio, R.J., Bryant, A.S., Ohja, B. and Bartolucci, A.A. (2005) The Maximum Standardized Uptake Values on Positron Emission Tomography of a Non-Small Cell Lung Cancer Predict Stage, Recurrence, and Survival. The Journal of Thoracic and Cardiovascular Surgery, 130,151-159. http://dx.doi.org/10.1016/j.jtcvs.2004.11.007

[18] Okereke, I.C., Gangadharan, S.P., Kent, M.S., Nicotera, S.P., Shen, C. and DeCamp, M.M. (2009) Standard Uptake Value Predicts Survival in Non-Small Cell Lung Cancer. Annals of Thoracic Surgery, 88, 911-915. http://dx.doi.org/10.1016/j.athoracsur.2009.05.083

[19] Ahuja, V., Coleman, R.E., Herndon, J. and Patz Jr, E.F. (1998) The Prognostic Significance of Fluorodeoxyglucose Positron Emission Tomography Imaging for Patients with Non-Small Cell Lung Carcinoma. Cancer, 83, 918-924. http://dx.doi.org/10.1002/(SICI)1097-0142(19980901)83:5<918::AID-CNCR17>3.0.CO;2-Y

[20] Vansteenkiste, J.F., Stroobants, S.G., De Leyn, P.R., Verbeken, E.K., Deneffe, G.J., Mortelmans, L.A. and Demedts, M.G. (1999) Prognostic Importance of the Standardized Uptake Value on 18F-Fluoro-2-deoxy-glucose-positron emission Tomography Scan in Non- Small Cell Lung Cancer: An Analysis of 125 Cases. Journal of Clinical Oncology, 17, 3201-3206.

[21] Dhital, K., Saunders, C.A., Seed, P.T., O’Doherty, M.J. and Dussek, J. (2000) 18Fluorodeoxyglucose Positron Emission Tomography and Its Prognostic Value in Lung Cancer. European Journal Cardio-Thoracic Surgery, 18, 425-428. http://dx.doi.org/10.1016/S1010-7940(00)00535-2

[22] Hicks, R.J., Kalff, V., MacManus, M.P., Ware, R.E., Hogg, A., McKenzie, A.F., Matthews, J.P. and Ball, D.L. (2001) 18F-FDG PET Provides High-Impact and Powerful Prognostic Stratification in Staging Newly Diagnosed Non-Small Cell Lung Cancer. Journal of Nuclear Medicine, 42, 1596-1604.

[23] Higashi, K., Ueda, Y., Arisaka, Y., Sakuma, T., Nambu, Y., Oguchi, M., Seki, H., Tonami, H. and Yamamoto, I. (2002) 18F-FDG Uptake as a Biologic Prognostic Factor for Recurrence in Patients with Surgically Resected Non-Small Cell Lung Cancer. Journal of Nuclear Medicine, 43, 39-45.

[24] Jeong, H.J., Min, J.J., Park, J.M., Chung, J.K., Kim, B.T., Jeong, J.M., Lee, D.S., Lee, M.C., Han, S.K. and Shim, Y.S. (2002) Determination of the Prognostic Value of 18F-Fluorodeoxyglucose Uptake by Using Positron Emission Tomography in Patients with Non-Small Cell Lung Cancer. Nuclear Medicine Communications, 23, 865-870. http://dx.doi.org/10.1097/00006231-200209000-00010

[25] Borst, G.R., Belderbos, J.S., Boellaard, R., Comans, E.F., De-Jaeger, K., Lammertsma, A.A. and Lebesque, J.V. (2005) Standardised FDG Uptake: A Prognostic Factor for Inoperable Non-Small Cell Lung Cancer. European Journal of Cancer, 41, 1533-1541. http://dx.doi.org/10.1016/j.ejca.2005.03.026

[26] Eschmann, S.M., Friedel, G., Paulsen, F., Reimold, M., Hehr, T., Budach, W., Scheiderbauer, J., Machulla, H.J., Ditt- 
mann, H., Vonthein, R. and Bares, R. (2006) Is Standardised 18F-FDG Uptake Value an Outcome Predictor in Patients with Stage III Non-Small Cell Lung Cancer? European Journal of Nuclear Medicine and Molecular Imaging, 33, 263269. http://dx.doi.org/10.1007/s00259-005-1953-2

[27] Kramer, H., Post, W.J., Pruim, J. and Groen, H.J.M. (2006) The Prognostic Value of Positron Emission Tomography in Non-Small Cell Lung Cancer: Analysis of 266 Cases. Lung Cancer, 52, 219-224. http://dx.doi.org/10.1016/j.lungcan.2005.12.011

[28] Um, S.W., Kim, H., Koh, W.J., Suh, G.Y., Chung, M.P., Kwon, O.J., Choi, J.Y., Han, J., Lee, K.S. and Kim, J. (2009) Prognostic Value of 18F-FDG Uptake on Positron Emission Tomography in Patients with Pathologic Stage I NonSmall Cell Lung Cancer. Journal of Thoracic Oncology, 4, 1331-1336. http://dx.doi.org/10.1097/JTO.0b013e3181b6be3e

[29] Uehara, H., Tsutani, Y., Okumura, S., Nakayama, H., Adachi, S., Yoshimora, M., Miyata, Y. and Okada, M. (2013) Prognostic Role of Positron Emission Tomography and High-Resolution Computed Tomography in Clinical Stage IA Lung Adenocarcinoma. Annals of Thoracic Surgery, 96, 1958-1965. http://dx.doi.org/10.1016/j.athoracsur.2013.06.086

[30] Hanin, F.X., Loneux, M., Cornet, J., Noirhomme, P., Coulon, C., Distexhe, J. and Poncelet, A.J. (2008) Prognostic Value of FDG Uptake in Early Stage Non-Small Cell Lung Cancer. Journal of Cardiothoracic Surgery, 33, 819-823. http://dx.doi.org/10.1016/j.ejcts.2008.02.005

[31] Nair, V.S., Krupitskaya, Y. and Gould, M.K. (2009) Positron Emission Tomography 18F-Flourodeoxyglucose Uptake and Prognosis in Patients with Surgically Treated Stage I Non-Small Cell Lung Cancer: A Systematic Review. Journal of Thoracic Oncology, 4, 1473-1479. http://dx.doi.org/10.1097/JTO.0b013e3181bccbc6 